\title{
Vasculitis Retinae- A Rare Presentation of SLE
}

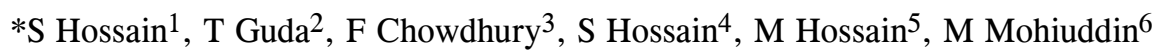

\begin{abstract}
Systemic lupus erythematosus (SLE) is a rare complex autoimmune disease characterized by autoantibody formation against double strand DNA and antinuclear antibody (ANA), complement activation, and deposition of immune complexes in tissues and organs. In normal population only $0.03 \%$ suffer from SLE, among them $90 \%$ are female between the age of 20 to 30 yrs. SLE can involve any region of the visual system. Although ocular manifestations are not part of the classification criteria for SLE but retinal involvement is the most common intraocular lesion observed in up to one-third of SLE patients. The most common extra ocular lesion is keratoconjunctivitis sicca. Ocular manifestations are rarely reported at the time of disease onset, but are usually associated with active generalized systemic disease. Due to low frequency of SLE and only one third of them have ocular involvement, so reports about retinal vasculitis are very rare. But fortunately a case of Vasculitis retinae due to SLE was admitted in Anwer Khan Modern Medical College \& Hospital on 04/12/2018.
\end{abstract}

Key Words: Systemic lupus erythematosus, Retinal vasculitis, Vasculitis retinae, autoimmune disease.

\section{Introduction}

Systemic lupus erythematosus (SLE) is a chronic, autoimmune, immune complex disease of the connective tissue and may affect almost any part of the visual system. ${ }^{1}$ Although ocular manifestations are not part of the classification criteria, they can be observed in up to one-third of patients with SLE. ${ }^{2,3,4}$ Ocular lesions (cotton wool spots, disc hyperemia, white retinal patches) in SLE were first described in 1929 by R. Bergmeister. ${ }^{5}$ Due to its infrequency we report a case of vasculitis retinae as a manifestation of SLE.

Herein, a 26-year-old woman with a recent flare-up of SLE presented with retinal vasculitis during her eye check-up. Though she was on a tapering dose of immunosuppressive agents her left eye got affected. Her visual acuity of right eye was good but her visual acuity of left eye was very poor. With proper examination and investigations her Vasculitis retinae of left eye was diagnosed.

\section{Case History}

Shilpi Rani Das, 26 years old female was relatively well 2 months back, then she developed low grade fever with multiple joints pain of both limbs which were not symmetrical and migratory. Then she suddenly developed high grade fever (HRT-103 ${ }^{\circ} \mathrm{f}$ ), generalized body swelling and body ache with fatigue for last 9 days and she was admitted in Dhaka Medical College \& hospital. After 2 days of admission she developed sudden dimness of vision in left eye with rashes all over the body, more marked at the sun exposed area and was diagnosed as a case of SLE.

1Prof. Dr. Sanwar Hossain, Professor \& Head, Department of Ophthalmology, AKMMC. drsanwar.h@gmail.com

${ }^{2}$ Dr. Titus Leonard Guda, Registrar, Department of Ophthalmology,

${ }^{3}$ Dr. Forhad Chowdhury, Medical officer, Department of Ophthalmology, AKMMCH

${ }^{4} \mathrm{Dr}$. Md. Somir Hossain, Honorary Medical Officer, NIO \&H

${ }^{5}$ Dr. Mehran Hossain, Consultant of Dermatology, City Hospital Limited

${ }^{6}$ Dr. Md Mohiuddin, Assistant Professor, Department of Nephrology, AKMMCH

*Corresponding Author

Date of submission: 1.02.2019 Date of acceptance: 17.04.2019

AKMMC J 2019; 10(2) : 179-182 
On examination, she was ill looking and anemic, generalized body ache with pain in both large joints (ankle, elbow and wrist) and small joints (metacarpophalangeal, proximal interphalangeal and distal interphalangeal). There was exfoliation or peeling of skin over both cheek with reddish patch present on both side of cheek spearing nasolabial fold and which was butterfly like pattern and hyperpigmented patch present over middle of forehead \& ala, alar rim and columella of nose [Fig: 1.A]. Exfoliation of skin, hyperpigmented patchy areas are present mostly on the extensor surface of both arms and forearms [Fig: 1.C]. Erosion and fissure present on both medial and lateral side of both upper and lower lips [Fig: 1.B].
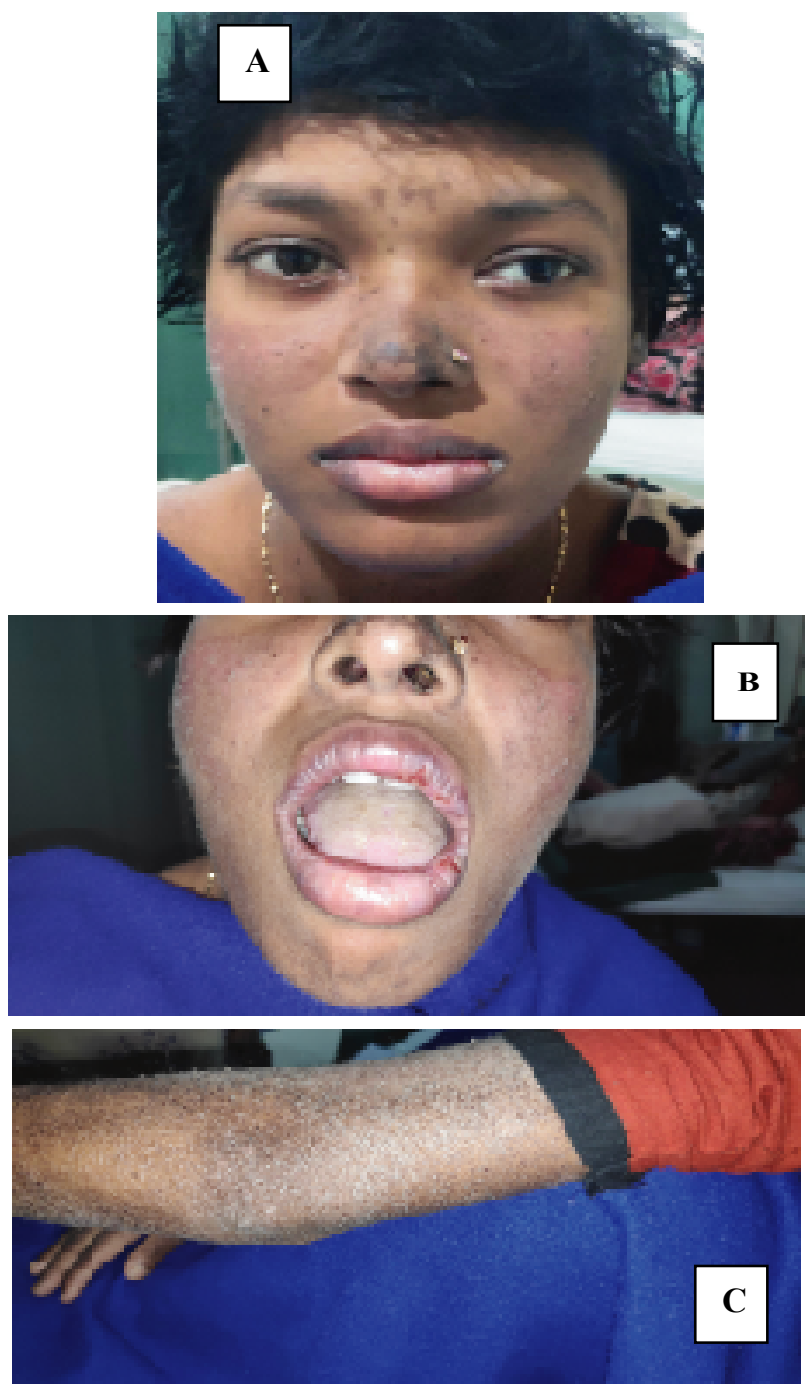

Figure 1: A) Exfoliation or peeling of skin over both cheek with reddish patch present on both side of cheek spearing nasolabial fold and which was butterfly like pattern and hyperpigmented patch present over middle of forehead \& ala, alar rim and columella of nose. B) Erosion and fissure present on both medial and lateral side of both upper and lower lips. C) Exfoliation of skin, hyperpigmented patchy areas are present mostly on the extensor surface of both arms and forearms.

On ocular examination her visual acuity of left eye reduced to hand movement and on Fundoscopic examination retinal vasculitis was found in the left eye. Right eye seems to be normal.

\begin{tabular}{lll}
\hline & Right eye & Left eye \\
\hline Visual acuity & 6/6 with glass & Hand movement \\
Pupil & Normal & Normal \\
Ocular motility & Full in all gaze & Full \\
Conjunctiva & Normal & Normal \\
Fundus & Normal & Vasculitis Retinae \\
Anterior Uveitis & Absent & Absent \\
Hypopyon & Absent & Absent \\
\hline
\end{tabular}

We have done some laboratory investigations which shows some positive findings for diagnosing SLE and they are $\mathrm{Hb} \%-7.1 \mathrm{~g} / \mathrm{dl}, \mathrm{WBC}: 4.10 \times 10^{\wedge} 9 / \mathrm{L}$, RBC: $3.06 \times 10^{\wedge} 12 / \mathrm{L}$, Platelet: $96 \times 10^{\wedge} 9 / \mathrm{L}$, Neutrophil: $48 \%$, Random blood sugar: $4.8 \mathrm{mmol} / \mathrm{l}$, Sodium $132 \mathrm{mmol} / \mathrm{l}$, SGPT : $53 \mathrm{U} / \mathrm{I}$, Serum creatinine $0.9 \mathrm{mg} / \mathrm{dl}$, Hbs Ag, HIV Ab, Anti HCV $\mathrm{Ab} \& \mathrm{VDRL}$ all were negative. Urine routine \& microscopic examination Shows haematuria, proteinuria and cast. ECG was normal. Some specific investigations were also done such as Antids-DNA:132.5 u/ml (Positive $>75 \mathrm{u} / \mathrm{ml}$, normal value: $\quad 30-75 \mathrm{u} / \mathrm{ml})$, ANA: $28.5 \mathrm{u} / \mathrm{ml}$ (positive $>10 \mathrm{u} / 1$, normal value: $<10 \mathrm{u} / \mathrm{l}$ ). We have also done some ocular investigations for establishing the diagnosis of vasculitis retinae and they are:

OCT:

1) Exudative retinal detachment of left eye [Fig: 2].

2) Normal retina of right eye .

Color fundus photography: Vasculitis Retinae of left eye and normal fundus in right eye [Fig: 3]. 


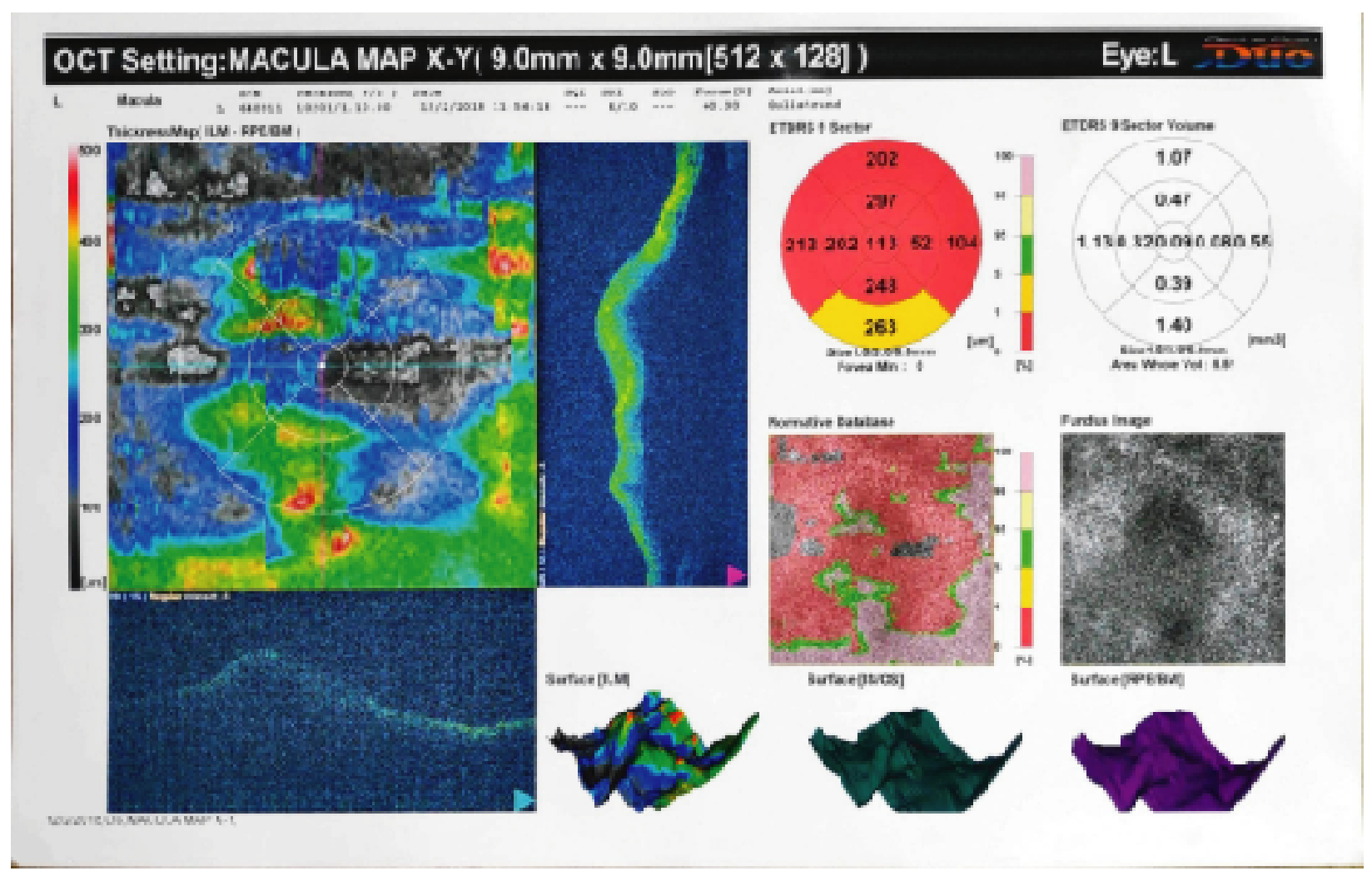

Figure 2: Exudative retinal detachment of left eye
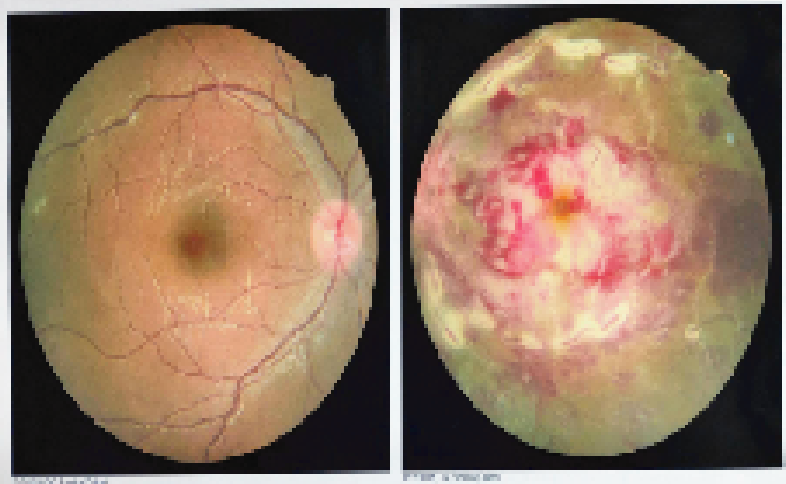

Figure 3: Vasculitis retinae with white patch of left eye and normal fundus in right eye

\section{Discussion}

Systemic lupus erythematosus (SLE) is relatively rare auto-immune disorder that may affect multiple organ systems, including the eye. Only $0.03 \%$ of the normal population suffers from SLE. Among them $90 \%$ are female. Among the eleven criteria's, at least four must be present for SLE diagnosis. In this case SLE diagnosis is based on the presence of
1. Malar rash of facial skin 2. Discoid rash on extensor surface of upper limbs 3. Oral ulcer with abdominal pain 4. Polyarthralgia 5. Haematological disorder eg.neutropenia 6. Immunological positive finding eg. Anti ds DNA $132.5 \mathrm{u} / \mathrm{ml}$ (Positive $>75 \mathrm{u} / \mathrm{ml}$, normal value: $30-75 \mathrm{u} / \mathrm{ml}){ }^{7}$ Positive ANA test: $28.5 \mathrm{u} / \mathrm{ml}$ (positive $>10 \mathrm{u} / 1$, normal value: $<10 \mathrm{u} / \mathrm{l}) 8$. Renal involvement.

Although ocular manifestations are not part of the classification criteria, ocular findings can be observed in up to one-third of patients with SLE2.3,4 The most common ophthalmic manifestation of SLE is keratoconjunctivitis sicca (dry eye syndrome). ${ }^{5,6}$ The most common intraocular manifestation is retinopathy (cotton wool spots, disc hyperemia, white retinal patches) with microangiopathy due to blood vessel occlusion ${ }^{7,8}$, but other ophthalmic manifestations may occur as well (e.g., uveitis, scleritis, episcleritis, choroidopathy). In this case vasculitis with haemorrhage and white retinal patch are found at the central retina of left eye. The incidence of SLE- associated retinopathy has been reported to be $7-29 \%$ among adult SLE patients ${ }^{8,9}$, 
while occlusive retinopathy has been found in approximately $3-11 \%$ of SLE patients. ${ }^{9,10}$ FFA shows this is a case of occlusive retinopathy which is very rare.

In SLE the retinal arteries are more frequently affected than vein ${ }^{11}$ but here both retinal vein and artery are involved. Usually posterior vitreous cells are present in retinal vasculitis but absent in this case. Other features of occlusive retinal vasculitis like cotton wool spots (representing nerve fiber layer infarcts) absent but retinal hemorrhages, optic nerve head swelling ${ }^{11,12,13}$ present [fig.3]. Other findings, which may present later in the course of the disease, include microaneurysms, neovascularization related to ischemia, and tractional retinal detachment is absent but in this case OCT macular region shows exudative retinal detachment [fig.2].

The SLE patients who developed retinopathy had a lower survival rate as compared to patients without retinopathy over the same time period. Moreover, active CNS involvement in SLE, a significant cause of patient morbidity. ${ }^{9,10}$ So unfortunately this patient is a victim of high morbidity,

\section{Conclusion}

The occurrence of vasculitis retinae as a manifestation of SLE is very rare all over the world. As an autoimmune disease where females are most often affected, it causes great suffering for the patient as it has limited treatment modalities. Patients of SLE with retinopathy had a lower overall survival rate as compared to patients without retinopathy. The participation of ophthalmologist/neuro-ophthalmologist, rheumatologist, dermatologist and other health professionals should all be involved in the management and follow up of patients of SLE with vasculitis retinae. Early recognition of retinal changes as well as early rheumatologic and ophthalmologic intervention may result in better outcomes. It is possible that inclusion of ocular manifestations among the classification criteria for SLE would enable earlier establishment of the diagnosis and therapeutic interventions in some instances of SLE and may minimize mortality from this disease.

\section{Conflict of interest: None}

\section{References}

1. Monov S, Monova D. Classification criteria for neuropsychiatric systemic lupus erythematosus: do they need a discussion? Hippokratia 2008; 12: 103-7.

2. Bajwa A, Foster CS. Ocular manifestations of systemic lupus erythematosus. J Clin Cell Immunol 2014; 5:191.

3. Palejwala NV, Walia HS, Yeh S. Ocular manifestations of systemic lupus erythematosus: a eeview of the literature. Autoimmune Dis 2012; 290898.

4. Read RW. Clinical mini-review: systemic lupus erythematosus and the eye. Ocul Immunol Inflamm 2004; 12: 87-99.

5. Bergmeister R. Uber primare and miliare Tuberkulose der Retina. Wien Med Schnschr 1929; 79: 1116-9.

6. Mills JA: Systemic lupus erythematosus. N Eng J Med 1994, 330(26):1871-9. Epub 1994/06/30.

7. Stafford-Brady FJ, Urowitz MB, Gladman DD, et al: Lupus retinopathy. Patterns, associations, and prognosis. Arthritis Rheum 1988, 31(9): 1105-10. Epub 1988/09/01.

8. Lanham JG, Barrie T, Kohner EM, et al. SLE retinopathy: evaluation by fluorescein angiography. Ann Rheum Dis 1982, 41(5): 473-8. Epub 1982/ 10/01.

9. Ermakova NA, Alekberova ZS, Kosheleva NM, et al. Characteristics of retinal vascular involvement in systemic lupus erythematosus. Vestn Oftalmol 2001, 117(2): 21-4. Epub 2001/08/21. Osobennosti porazheniia sosudov setchatki pri sistemnoi krasnoi volchanke.

10. Abu El-Asrar AM, Herbort CP, Tabbara KF: Retinal vasculitis. Ocul Immunol Inflamm 2005, 13(6): 415-33. Epub 2005/12/03.

11. Gold DH, Morris DA, Henkind P: Ocular findings in systemic lupus erythematosus. Br J Ophthalmol 1972, 56(11): 800-4. Epub 1972/11/01.

12. Ushiyama $\mathrm{O}$, Ushiyama $\mathrm{K}$, Koarada $\mathrm{S}$, et al. Retinal disease in patients with systemic lupus erythematosus. Ann Rheum Dis 2000, 59(9): 7058. Epub 2000/09/08.

13. Anaya J-M, Talal N: Head and neck findings in SLE: Sjogren's syndrome and the eye, ear, and larynx. In Dubois' Lupus Erythematosus. 5th edition. Edited by Wallace DJ, Hahn BH. Baltimore: Williams and Wilkins; 1997:783-91. 